Conclusions: Adverse childhood experiences are reported frequently in individuals with SLE; accumulation of adverse experiences is associated with poor SLE outcomes. Higher scores in each domain, especially childhood neglect or abuse, were associated with poorer health measures in adulthood. Further research regarding ACE patterns and SLE outcomes is warranted.

Disclosure of Interest: None declared

DOI: 10.1136/annrheumdis-2017-eular.5568

\section{THU0601 CARDIOVASCULAR SCREENING AMONG PATIENTS WITH INFLAMMATORY ARTHRITIS: TO WHAT EXTENT DO PATIENTS FOLLOW RECOMMENDATIONS?}

A.H. Kjeldgaard $^{1}$, K. Hørslev-Petersen ${ }^{1}$, R.D. Christensen ${ }^{2}$, J. Søndergaard ${ }^{2}$, J. Primdahl ${ }^{3}$. ${ }^{1}$ King Christian X's Hospital for Rheumatic Diseases, Graasten;

${ }^{2}$ Research Unit for General Practice, University of Southern Denmark, Odense; ${ }^{3}$ King Christian X's Hospital for Rheumatic Disease, Graasten, Denmark

Background: Patients with inflammatory arthritis (IA) have a substantially increased risk for cardiovascular (CV) disease and consequently regular screening is recommended (1).

Objectives: To investigate whether patients with known IA and high CV risk follow the recommendation, given in a nurse-led CV risk screening consultation, to consult General Practice in order to reduce their CV risk. Furthermore to investigate the influence of socioeconomic position and gender.

Methods: A register-based cohort study comprising outpatients at King Christian X's Hospital for Rheumatic Diseases, Graasten, Denmark, diagnosed with rheumatoid arthritis (RA), psoriatic arthritis (PsA) or spondylo arthritis ( $\mathrm{SpA})$, who had participated in at least one screening consultation based on the EULAR recommendations (1) between 1st of July 2012 and 1st of July 2015. The primary outcome was a consultation with their GP and at least one intervention of relevance for CV risk within 3 months after the screening consultation.

Results: 1266 patients, $18-85$ years of age, were included; $72.5 \%$ with RA and $27.5 \%$ with SpA or PsA. Of the 447 (35\%) with high risk of CV disease, $60 \%$ consulted GP after the screening visit compared to $55 \%$ for the 819 patients with low risk of CV disease. Of the $60 \%$ of patients with high risk who consulted their $\mathrm{GP}, 41 \%$ had at least one relevant intervention. Education $\geq 10$ years increased the odds for non-compliance (Odds Ratio [Confidence interval]) $(0.72$ [0.56;0.92], $\mathrm{p}=0.01)$ and age above 65 years increased the odds for compliance $(1.50$ [1.15;1.95], $p=0.03)$. Income, diagnosis, gender, Low Density Lipoprotein level and systolic blood pressure did not significantly influence the odds to consult their GP after the screening consultation. Among high risk patients, $7.4 \%$ had their blood glucose checked at a GP consultation and 6.3\% had their blood-pressure measured with at-home equipment after the screening consultation as opposed to $4.8 \%$ and $1 \%$ among low risk patients.

Conclusions: After a screening consultation, $40 \%$ of the patients with high risk of CV disease did not consult their GP at all in the following 3 months. At least $33 \%$ of the patients with high risk followed the recommendations to consult their GP and $27 \%$ consulted their GP for reasons not possible to clarify in this study. Only age and higher education had a significant influence on the outcome.

\section{References:}

[1] Peters, M.J., et al., EULAR evidence-based recommendations for cardiovascular risk management in patients with rheumatoid arthritis and other forms of inflammatory arthritis. Ann Rheum Dis, 2010. 69(2): p. 325-31.

Acknowledgements: We would like to thank The Danish Rheumatism Association and the Henrik Henriksens fund for financial support for this study.

Disclosure of Interest: None declared

DOI: 10.1136/annrheumdis-2017-eular.1908

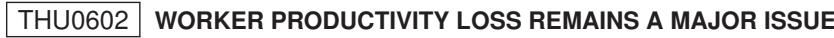 FOR PATIENTS WITH INFLAMMATORY ARTHRITIS AND OSTEOARTHRITIS: RESULTS FROM THE INTERNATIONAL EULAR-PRO WORKER PRODUCTIVITY STUDY}

S. Leggett ${ }^{1}$, A. Bosworth ${ }^{2}$, C. Hoffstetter ${ }^{3}$, A. Boonen ${ }^{4}$, D. Lacaille ${ }^{5}$, C. Mihai ${ }^{6}$ C. Talli ${ }^{7}$, S. Hagel $^{8}$, G. Crepaldi ${ }^{9}$, S. Ramiro ${ }^{10}$, S. Dadoun ${ }^{11}$, S. Verstappen ${ }^{12,13}$ on behalf of EULAR-PRO at-work productivity co-investigators. ${ }^{1}$ Arthritis Research UK Centre for Epidemiology, University of Manchester, Manchester; ${ }^{2}$ NRAS, Maidenhead, United Kingdom; ${ }^{3}$ OMERACT, Ontario, Canada; ${ }^{4}$ Division of Rheumatology, Maastricht University Medical Centre, Maastricht, Netherlands; ${ }^{5}$ Arthritis Research Centre of Canada, University of British Columbia, Vancouver, Canada; ${ }^{6}$ Internal Medicine and Rheumatology Clinic, Dr. Ion Cantacuzino Hospital, Carol Davila University of Medicine and Pharmacy, Bucharest, Romania; ${ }^{7}$ Rheumatology, East Tallinn Central Hospital, Tallin, Estonia; ${ }^{8}$ Department of Clinical Sciences Lund, Section of Rheumatology, Lund University and Skane University hospital, Lund, Sweden; ${ }^{9}$ Division of Rheumatology, IRCCS Policlinico San Matteo Foundation, Pavia, Italy; ${ }^{10}$ Leiden University Medical Centre, Leiden, Netherlands; ${ }^{11}$ APHP Pitie-Salpetriere Hospital, Department of Rheumatology, Paris, France; ${ }^{12}$ Arthritis Research UK Centre for Epidemiology, University of Manchester; ${ }^{13} \mathrm{NIHR}$ Manchester Musculoskeletal BRU, Central Manchester Univ. Hospitals NHS Foundation Trust, Manchester, United Kingdom

Background: Rheumatic and Musculoskeletal Diseases such as Inflammatory arthritis (IA) and osteoarthritis (OA) are one of the biggest causes of disability and worker productivity loss which has recently been recognized by European policy makers and the World Health Organization (WHO). However, limited information is available about job characteristics and the level of both presenteeism and absenteeism in employed persons with IA or OA across countries.

Objectives: To describe job characteristics and worker productivity loss in patients with IA and OA in Europe and Canada.

Methods: Patients with IA or OA in paid employment from seven countries within Europe and from Canada were recruited to the EULAR-PRO Worker productivity study. Patients completed a questionnaire including questions about their job, job characteristics and the Work Productivity and Activity Impairment Questionnaire (WPAI) measuring percent hours absent and the percentage their disease affected productivity while working $(0-100 \%=$ disease completely prevented work). Patients also completed several health-related patient reported outcome measures, including: the Health Assessment Questionnaire (HAQ), Visual Analogue Scale (VAS) general well-being, and EuroQol-5D (EQ-5D).

Results: 503 patients were included in this large international study. Mean (SD) age was $47(10)$ years, median [IQR] disease duration $12[5,21]$ years and $94 \%$ had IA. $42 \%$ had a predominately mentally demanding job, $10 \%$ physically demanding job, and $48 \%$ a combination; with overall $34 \%$ reporting their job being very demanding (see table for country specific results). Respectively $12 \%$ and $5 \%$ of patients were able to often or always postpone work tasks if need be, whilst, respectively $19 \%$ and $51 \%$ never or sometimes received help from colleagues which may depend on job/employment type and company size. Twenty-one\% of patients reported that they missed time off work due to ill-health in the past week (median [IQR] \% time missed due to ill-health 20\% [9-50]). Interestingly, a total of $11 \%$ were unsatisfied with their current job; and $23 \%$ of patients did not disclose their disease to their employer.

\begin{tabular}{|c|c|c|c|c|c|c|c|c|}
\hline & $\begin{array}{l}\text { United Kingdom } \\
\qquad N=76\end{array}$ & $\begin{array}{l}\text { France } \\
N=45\end{array}$ & $\begin{array}{l}\text { Netherlands } \\
N=96\end{array}$ & $\begin{array}{l}\text { Estonia } \\
N=81\end{array}$ & $\begin{array}{l}\text { Sweden } \\
N=66\end{array}$ & $\begin{array}{c}\text { Romania } \\
N=62\end{array}$ & $\begin{array}{l}\text { Italy } \\
\mathrm{N}=31\end{array}$ & $\begin{array}{l}\text { Canada } \\
N=46\end{array}$ \\
\hline Age, years & $48(8)$ & $46(10)$ & 49(11) & $46(11)$ & $49(9)$ & $42(9)$ & $47(9)$ & $51(9)$ \\
\hline Gender, female & $53 \%$ & $60 \%$ & $54 \%$ & $62 \%$ & $73 \%$ & $55 \%$ & $84 \%$ & $83 \%$ \\
\hline VAS well being, mm & $39[21-60]$ & $28[18-49]$ & $30[11-60]$ & $43[20-62]$ & $38[20-61]$ & $35[12.55]$ & $32[14 \cdot 65]$ & $28[15 \cdot 60]$ \\
\hline HAQ-score & $0.63[0.25 \cdot 1]$ & $0.25[0.13-0.63]$ & $0.38[0.0 .5]$ & $0.38[0.1-0.75]$ & $0.63[0.38-88]$ & $0.13[0.0 .63]$ & $0.25[0.0 .5]$ & $0.5[0.13 \cdot 1]$ \\
\hline$E 0.50$ & $0.62[0.57-0.69]$ & $0.69[0.66-0.73]$ & $0.73[0.62-0.73]$ & $0.66[0.52-0.73]$ & $0.66[0.62-0.73]$ & $0.69[0.62-0.90]$ & $0.69[0.62-0.88]$ & $0.62[0.55-0.73]$ \\
\hline \multicolumn{9}{|l|}{ General job demands: } \\
\hline Slightlydemanding & $12 \%$ & $11 \%$ & $34 \%$ & $66 \%$ & $12 \%$ & $16 \%$ & $7 \%$ & $20 \%$ \\
\hline Demanding & $41 \%$ & $40 \%$ & $40 \%$ & $30 \%$ & $41 \%$ & $54 \%$ & $50 \%$ & $33 \%$ \\
\hline $\begin{array}{l}\text { Vervdemanding } \\
\text { Jobsatisfaction: }\end{array}$ & $47 \%$ & $49 \%$ & $26 \%$ & $4 \%$ & $47 \%$ & $30 \%$ & $43 \%$ & $47 \%$ \\
\hline Satisfied & $57 \%$ & $78 \%$ & $84 \%$ & $81 \%$ & $67 \%$ & $74 \%$ & $73 \%$ & $71 \%$ \\
\hline Neutral & $19 \%$ & $11 \%$ & $11 \%$ & $13 \%$ & $17 \%$ & $21 \%$ & $17 \%$ & $11 \%$ \\
\hline Unsatisfied & $24 \%$ & $11 \%$ & $4 \%$ & $6 \%$ & $17 \%$ & $5 \%$ & $10 \%$ & $18 \%$ \\
\hline $\begin{array}{l}\text { \% Absent in previous } \\
\text { week due to ill-health }\end{array}$ & $16 \%$ & $20 \%$ & $15 \%$ & $26 \%$ & $23 \%$ & $18 \%$ & $26 \%$ & $33 \%$ \\
\hline $\begin{array}{l}\text { \% Work time misssed due } \\
\text { to illhealthx }\end{array}$ & $24[9 \cdot 100]$ & $20[13-34]$ & $50[19 \cdot 72]$ & $19[10-50]$ & $15[9.50]$ & $15[9.50]$ & $19[5.33]$ & $15[3.50]$ \\
\hline $\begin{array}{l}\text { Yimpaiment due to ill. } \\
\text { health while working } \\
\text { (WPA) F }\end{array}$ & $20[0.50]$ & $20[0.30]$ & $20[0.50]$ & $20[0.40]$ & $30[5.45]$ & $20[10 \cdot 50]$ & $20[0.50]$ & $20[10-60]$ \\
\hline 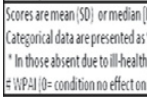 & $\begin{array}{l}\text { the: } \\
\text { in warkt-10=condition }\end{array}$ & athe distribution of & ed wod" " $100 \%$. & & & & & \\
\hline
\end{tabular}

Conclusions: This is one of the largest international studies investigating worker productivity loss in patients with IA and OA. It highlights the burden of the disease across countries and the importance of increasing awareness of rheumatological conditions in order to prevent presenteeism and long-term sick leave by providing the best available intervention to the individual patient in paid employment.

Disclosure of Interest: None declared

DOI: 10.1136/annrheumdis-2017-eular.5041

\section{THU0603 DISEASE BURDEN OF KNEE OSTEOARTHRITIS PATIENTS UNDERGOING JOINT REPLACEMENT COMPARED TO MATCHED CONTROLS: A POPULATION-BASED ANALYSIS OF A DUTCH MEDICAL CLAIMS DATABASE}

J.T.H. Nielen ${ }^{1,2,3}, \underline{A}$ Boonen ${ }^{4}$, P.C. Dagnelie ${ }^{1}$, B. van den Bemt ${ }^{5,6}$, P. Emans ${ }^{7}$, F. Lafeber ${ }^{8}$, W.E. van Spil ${ }^{8}$, F. de Vries ${ }^{2,3}$, P. Welsing $8,9 .{ }^{1}$ Epidemiology, Maastricht University; ${ }^{2}$ Clinical Pharmacy \& Toxicology, Maastricht University Medical Center, Maastricht; ${ }^{3}$ Pharmacoepidemiology \& Clinical Pharmacology, Utrecht University, Utrecht; ${ }^{4}$ Rheumatology, Maastricht University Medical Center, Maastricht; ${ }^{5}$ Pharmacy, Sint Maartenskliniek; ${ }^{6}$ Pharmacy, Radboud University Medical Center, Nijmegen; ${ }^{7}$ Orthopaedics, Maastricht University Medical Center, Maastricht; ${ }^{8}$ Rheumatology \& Clnical Immunology; ${ }^{9}$ Julius Center, Utrecht University Medical Center, Utrecht, Netherlands

Background: Knee osteoarthritis $(O A)$ is a progressive joint disease generally associated with increasing pain. In severe symptomatic knee OA, knee prosthesis 